\title{
ELECTROCARDIOGRAPHIC CHANGES ASSOCIATED WITH THE USE OF EPINEPHRINE DURING GENERAL ANAESTHESIA
}

\author{
Hilda Roberts, F.F.A.R.C.S., AND Krikor V. Boyagian, M.D. *
}

MANY OF THE DRUGS and techniques which are used to produce optimum conditions in particular spheres of operative surgery all too often have adverse effects on the patient. The more efficient the result, the more reluctant the exponent to modify the technique. The dangers inherent in the use of epinephrine, either during general anaesthesia or otherwise, have been expounded repeatedly in medical literature over the course of many decades. Katz ${ }^{1}$ maintains that, provided certain essential precautions are taken, the use of epinephrine is safe in man during general anaesthesia. He also says that all too often the desirable conditions are not present, resulting in the fatalities or near fatalities which continue to be reported.

In the field of cosmetic surgery, particularly facial reconstruction, the demand for an operating field which is as dry as possible is of paramount importance to the surgeon. Consequently, vasoconstrictors are used to a greater extent than in general surgery. Epinephrine is the drug of choice, used either alone or in conjunction with a local anaesthetic. The following presentation involves both uses of epinephrine in a series of cosmetic surgical procedures. The epinephrine was employed in three ways:

1. Two per cent lidocaine with epinephrine 1:100,000 solution was used subcutaneously.

2. Ten per cent cocaine with epinephrine 1:1,000 solution was used for topical application to the nares.

3. Epinephrine 1:100,000 solution was used to sponge the operative site during the procedure.

All patients were subjected to continuous cardiac monitoring using the Burdick electrocardiograph. Graphic records were made at specific times, and also whenever abnormal tracings were shown on the cardioscope. The points of recording are indicated in Table I. Serum potassium estimations were made on 35 patients during the course of anaesthesia; $\mathrm{pH}$ and $\mathrm{P}_{\mathrm{CO}_{2}}$ values were measured in 11 patients.

The number of patients observed was 167 , of whom 52 were inpatients and 115 outpatients. The sex distribution was 142 females and 25 males. Other pertinent details are shown in Table I. These patients came to the operation in satisfactory physical condition, and in the few cases where an important illness had occurred in the past, the opinion of an internist was sought. However, in the case of outpatients it is not always easy to decide whether raised blood pressure and pulse rate just prior to operation are due entirely to nervousness or to some underlying pathology, and nearly all patients were in varying stages

-Department of Anaesthesia, Women's College Hospital, Toronto.

Can. Anaes. Soc. J., vol. 17, no. 6, November 1970 
of apprehension. Because of this uncertainty, a routine has been established whereby outpatients are examined by an internist several days before the date of operation.

\section{Method of ANAesthesia}

The preoperative medication in 36 inpatients varied considerably, and after different responses it was decided to eliminate preoperative drugs.

A preanaesthetic electrocardiographic record was made on all patients after they were placed on the operating table, using leads 1, 2, 3, avr, avL, avf. An intravenous infusion of lactated Ringer's solution was started in each case, and atropine $0.6 \mathrm{mg}$ injected intravenously in all except five patients. Of the latter, three received $0.4 \mathrm{mg}$, and the remaining two did not receive any atropine. Thiopentone administration ranged between 375 and $650 \mathrm{mg}$ depending on the needs of the patient, a sufficient amount being given to produce an adequate depth of anaesthesia. Light levels of anaesthesia were avoided. Succinylcholine 60 to $80 \mathrm{mg}$ was given and ventilation with oxygen was carried out until fasciculation was over. Endotracheal intubation was performed and the patient connected to the Bennett anaesthesia ventilator attached to a Boyle-type anaesthetic apparatus. The gas flow was nitrous oxide 3 to $4 \mathrm{~L} / \mathrm{min}$ and oxygen $2 \mathrm{~L} / \mathrm{min}$. Methoxyfluorane 1 per cent was delivered through a Pentec® vapourizer following intubation, then adjusted to 0.5 per cent or 0.2 per cent to provide the necessary depth of anaesthesia and to maintain a systolic blood pressure of 85 to $95 \mathrm{~mm} \mathrm{Hg}$ wherever possible throughout the operation. Halothane was administered in a similar manner. A moderate degree of hyperventilation was established. When there was evidence that the succinylcholine had ceased to be effective, d-tubocuraine chloride $15 \mathrm{mg}$ was administered. At the termination of operation most of the patients required neostigmine to reverse residual effects of the relaxant. When respiration was re-established and the patient extubated, meperidine $10 \mathrm{mg}$ and hydroxizine hydrochloride $40 \mathrm{mg}$ were administered intravenously. Experience has shown that this medication diminishes the restlessness of these patients in the recovery room. A final electrocardiographic recording was done before the patient left the operating table.

Local anaesthesia was employed by the surgeon, using methods described previously. The amount used and the technique employed varied with the type of operation performed. Lidocaine 2 per cent with epinephrine 1:100,000 was used as follows:

rhytidectomy and blepharoplasty: 30 to $40 \mathrm{ml}$ injected subcutaneously over a period of approximately 20 minutes;

blepharoplasty: 6 to $10 \mathrm{ml}$; rhytidectomy: 20 to $30 \mathrm{ml}$; rhinoplasty and submucous resection: 4 to $10 \mathrm{ml}$, with an average of $8 \mathrm{ml}$; otoplasty: $13 \mathrm{ml}$.

Whenever a rhinoplasty was performed, in addition to the subcutaneous injection the nares were packed with the solution of 10 per cent cocaine and epinephrine 1:1,000. Further, in all operations save rhinoplasty a solution of epinephrine 1:100,000 was used, as explained earlier. The amount varied from 90 
ROBERTS \& BOYAGIAN: ELECTROCARDIOGRAPHIC CHANGES WITH EPINEPHRINE 593

to $360 \mathrm{ml}$; however, it is difficult to say how much solution was lost during transfer of the sponge from bowl to patient.

\section{Results}

The number and type of changes in the electrocardiograms occurring during the course of anaesthesia and operation are set out in Table I in association with the various related factors. In the group under 20 years of age, 10 patients out of 20 exhibited frank abnormalities in the electrocardiogram. One of these showed premature ventricular contractions in the preanaesthetic recordings. The table shows that the abnormalities tended to occur at the times when one would expect an increase in cardiovascular irritability. Certain changes have not been recorded in the table. These were alterations in the configuration of the ST segment and flattening of the T-wave in some of the leads. These changes were seen associated with sinus tachycardia in five patients. Tachycardia was defined as a rate in excess of 100 beats per minute. A total of 137 patients

TABLE I

\begin{tabular}{|c|c|c|c|c|c|c|}
\hline & $\begin{array}{l}\text { Number } \\
\text { of } \\
\text { patients }\end{array}$ & $\begin{array}{l}\text { Premature } \\
\text { ventricular } \\
\text { contractions }\end{array}$ & $\begin{array}{l}\text { Right } \\
\text { bundle } \\
\text { branch } \\
\text { block }\end{array}$ & $\begin{array}{l}\text { Nodal } \\
\text { rhythm }\end{array}$ & $\begin{array}{c}\text { Premature } \\
\text { atrial } \\
\text { contractions }\end{array}$ & $\begin{array}{l}\text { Wandering } \\
\text { pacemaker }\end{array}$ \\
\hline \multicolumn{7}{|l|}{ Age group } \\
\hline $20-29$ & 43 & 17 & 1 & 4 & & 1 \\
\hline $30-39$ & $\begin{array}{l}70 \\
29\end{array}$ & 7 & & 4 & & 1 \\
\hline $40-49$ & 46 & 15 & 1 & 4 & 2 & \\
\hline $50-59$ & 23 & 4 & & & & 1 \\
\hline $60+$ & & & & 1 & & \\
\hline \multicolumn{7}{|l|}{ Type of anaesthesia } \\
\hline methoxyfluorane & 155 & 47 & 2 & 15 & 2 & 2 \\
\hline halothane & 12 & 4 & & 1 & & 1 \\
\hline \multicolumn{7}{|l|}{ Type of operation } \\
\hline SMR & 76 & 32 & 1 & 6 & 1 & \\
\hline $\begin{array}{l}\text { rhytidectomy } \\
\text { (total) }\end{array}$ & 37 & 8 & & 4 & 1 & \\
\hline blepharoplasty & 25 & $\begin{array}{l}8 \\
8\end{array}$ & 1 & $\begin{array}{l}4 \\
1\end{array}$ & & \\
\hline dermabrasion (face) & 6 & $\stackrel{0}{1}$ & & 1 & & \\
\hline otoplasty & 3 & & & 1 & & \\
\hline $\begin{array}{l}\text { reduction } \\
\text { mammoplasty }\end{array}$ & 8 & 1 & & 2 & & \\
\hline $\begin{array}{l}\text { mammoplasty } \\
\text { augmentation }\end{array}$ & & & & & & \\
\hline mammoplasty & 3 & & & & & \\
\hline other & 9 & 1 & & 1 & & \\
\hline \multirow{2}{*}{\multicolumn{7}{|c|}{$\begin{array}{l}\text { Time of occurrence of } \\
\text { cardiac arrhythmias }\end{array}$}} \\
\hline & & & & & & \\
\hline recording & & 9 & 2 & 1 & & 3 \\
\hline after atropine & & & & & 1 & \\
\hline af ter thiopentone & & & & 2 & & \\
\hline after succinylcholine & & 1 & & & & \\
\hline $\begin{array}{l}\text { during oxygenation } \\
\text { during intubation }\end{array}$ & & $\begin{array}{r}8 \\
20\end{array}$ & & & & \\
\hline after intubation & & 9 & & 2 & 1 & \\
\hline after local anaesthesia & & 1 & & $\overline{6}$ & & \\
\hline $\begin{array}{l}\text { after topical } \\
\text { nasal anaesthesia } \\
\text { during surgery }\end{array}$ & & 2 & & $\begin{array}{l}1 \\
4\end{array}$ & & \\
\hline Postoperative period & & 1 & 2 & & & 3 \\
\hline
\end{tabular}


demonstrated sinus tachycardia at some time during the course of the observations, and the most frequent point of occurrence was within the first 20 to 30 minutes of entry into the operating room. A moderate tachycardia persisted in 46 cases throughout operation. Arterial blood pressure changes assumed a fairly definite pattern, showing a rise of 10 to $30 \mathrm{~mm} \mathrm{Hg}$ following the administration of atropine. Any further increase was usually associated with the use of local anaesthetic drugs, and particularly with the topical application of cocaine and epinephrine to the nose. All hypertension had settled to an acceptable level within thirty minutes of occurrence, except in one patient. This outpatient, a woman 34 years of age, was extremely nervous preoperatively. Her blood pressure was 190/100 and she complained of increased intestinal activity since early morning. However, she said that this always happened when she became apprehensive. Her preanaesthetic recording was normal and the pulse rate 103 per minute. Immediately after intubation a few premature ventricular contractions were seen, and during surgery a mid-nodal rhythm developed. A normal recording was obtained at the end of the blepharoplasty. Her blood pressure did not fall below 140/90 during the operation, and in the recovery room rose to $180 / 100$. She was admitted and her condition was later identified as a well established hypertension

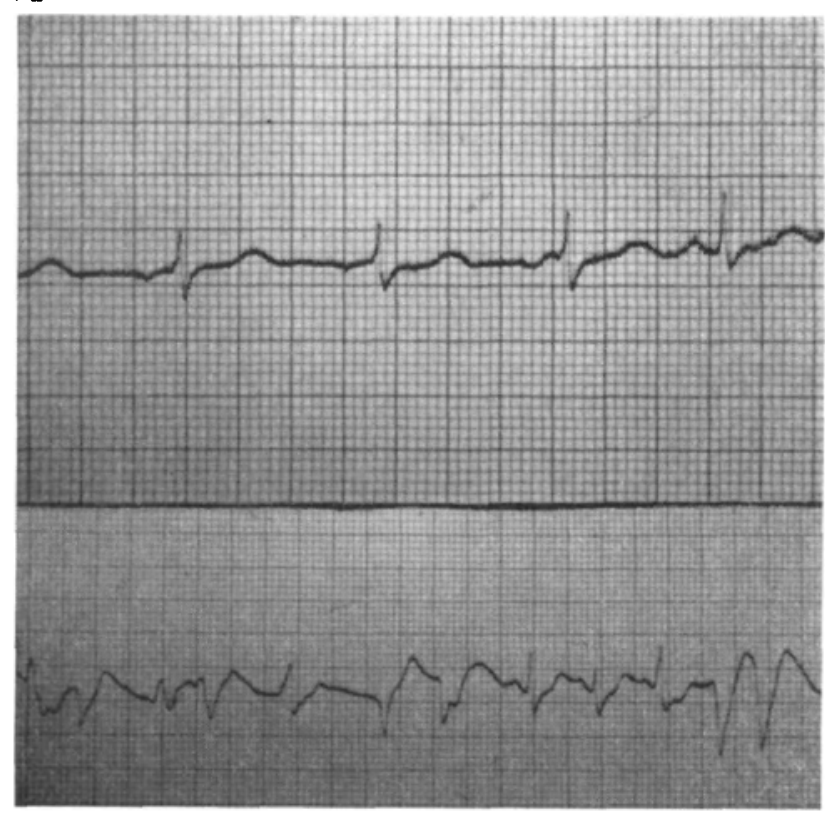

FIGURE 1. Twenty-nine-year-old female patient, rhinoplasty SMR, lead 2, halothane. Preinduction recording showed wandering pace maker (upper tracing). Following the application of local anaesthetic, subcutaneous and nasal, multifocal premature ventricular contractions appeared (lower tracing). The halothane was discontinued and the patient ventilated with oxygen. Meperidine $25 \mathrm{mg}$ and hydroxyzine hydrochlorine $100 \mathrm{mg}$ were given intravenously. Sinus rhythm followed. Halothane was reintroduced, and apart from an occasional episode of nodal rhythm, the recording was normal. Postoperative ECG was normal. 
Methoxyfluorane and halothane do not present unduly different results, but since the number of cases in each group varies considerably, one cannot draw any comparisons. The ECG recording shown in Figure 1 exhibited such marked

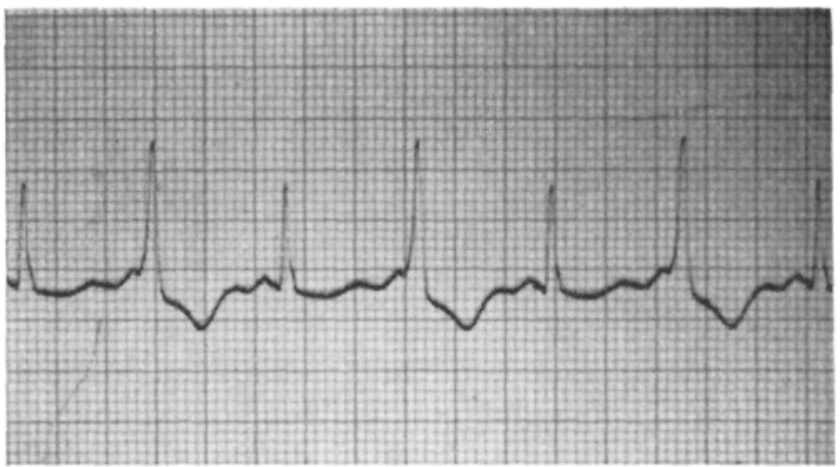

Figure 2. Forty-one-year-old female patient, abdominal wall reduction, lead 2, methoxyfluorane. Preinduction ECG showed regular sinus rhythm. Following intubation the recording showed ventricular bigeminy which subsided after ventilation was established. Postoperative recording was normal.

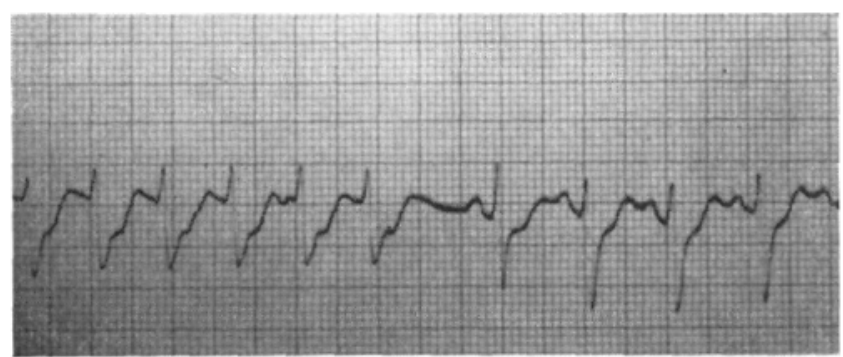

Figuke 3. Thirty-one-year-old female patient, rhinoplasty SMR, lead 2, methoxyfluorane. Preinduction ECG showed regular sinus rhythm. Supraventricular tachycardia followed the subcutaneous injection of 2 per cent lidocaine with epinephrine $1: 100,000$ and the nasal application of cocaine 10 per cent and epinephrine 1:1000. Normal recordings were obtained during surgery and postoperatively.

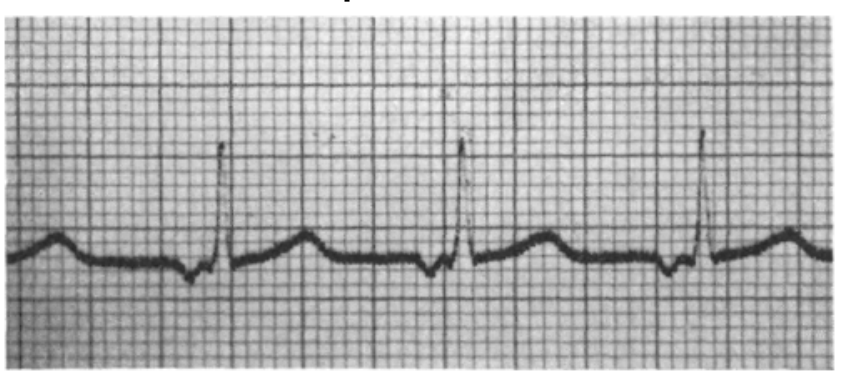

Figure 4. Thirty-six-year-old female patient, blepharoplasty, lead 2 , methoxyfluorane. Preinduction ECG showed regular sinus rhythm. Superior nodal rhythm followed injection of lidocaine 2 per cent with epinephrine $1: 100,000$, and persisted during surgery. Postoperative ECG showed persistence of nodal rhythm. 


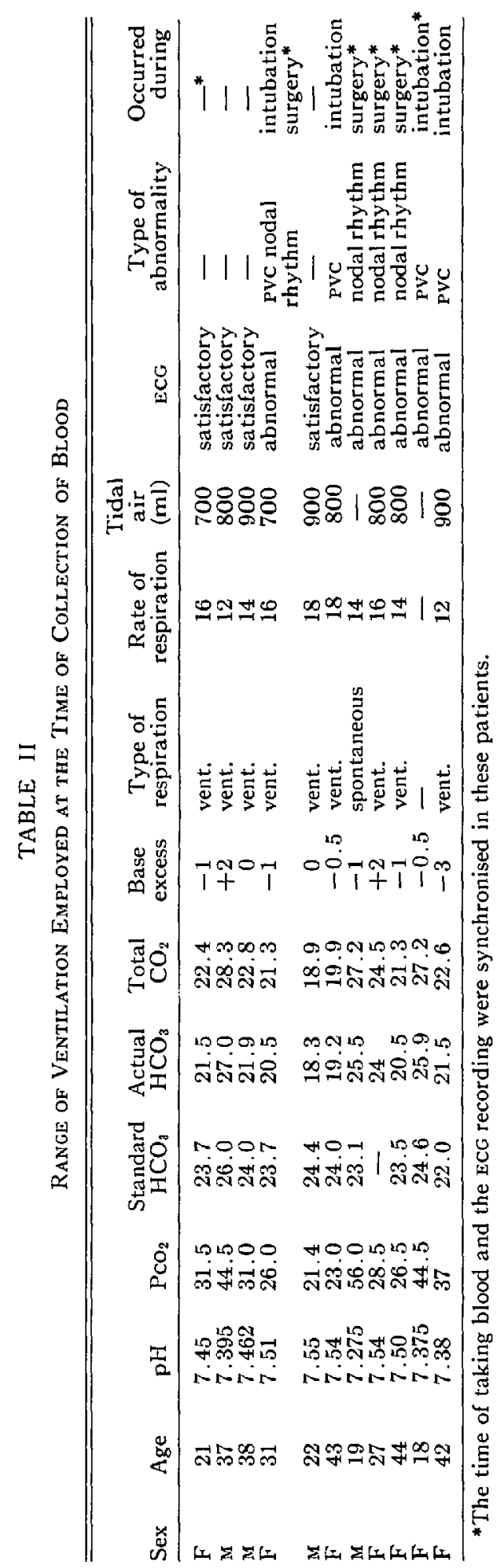


bouts of premature ventricular contractions during halothane anaesthesia that the halothane was discontinued and the patient was given meperidine $25 \mathrm{mg}$ and hydroxyzine hydrochloride $100 \mathrm{mg}$ intravenously. When the electrocardiogram showed only an occasional nodal rhythm, halothane was once more introduced into the circuit, without untoward results.

Serum potassium levels were measured in 33 patients during the course of anaesthesia, but the results did not show any significant change in circulating potassium. The $\mathrm{pH}$ and $\mathrm{P}_{\mathrm{CO}_{2}}$ values in 11 patients are set out in Table II.

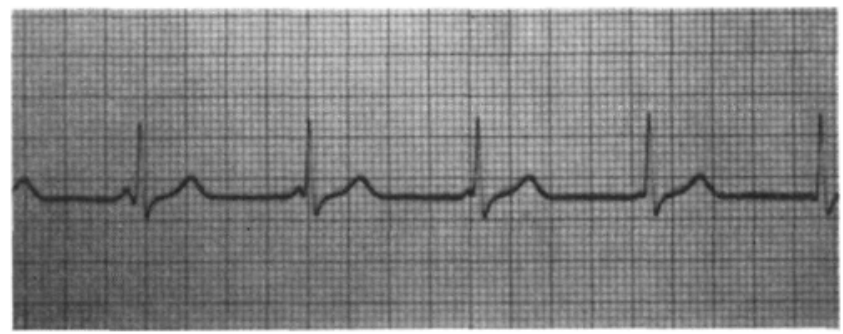

Figure 5. Twenty-one-year-old female patient, rhinoplasty and SMR, lead 2, methoxyfluorane. Preinduction ECG showed regular sinus rhythm. Wandering pace maker developed during subcutaneous injection of 2 per cent lidocaine with epinephrine $1: 100,000$. Reverted to normal after nasal packing, but periods of abnormality reoccurred at intervals throughout surgery. Postoperative recording was normal.

\section{Discussion}

Any abnormal electrocardiographic record obtained during anaesthesia and surgery can be interpreted only in conjunction with a preoperative record, the patient's medical condition and events which have surrounded the time of recording. Seldom can it be used alone to establish any real inefficiency of the conducting tissue of the heart. Therefore, to assess any changes which have been observed during this study, the same rules of evaluation must be applied.

Anaesthesia for operative procedures on an outpatient basis are nearly always involved with varying degrees of anxiety. According to Goldman, ${ }^{2}$ the anxiety reaction in patients with supposedly normal hearts can produce some electrocardiographic abnormalities, often associated with hyperventilation. Prolongation of the P-R interval and changes in the ST segments and in the $T$ wave may occur, the latter appearing chiefly in the left ventricular epicardial leads. The changes have been ascribed to imbalance of the autonomic system and can be restored to normal by atropine. Sinus tachycardia and arrhythmias of various types can also be associated with the anxiety state. Ten patients with sinus tachycardia before anaesthesia exhibited abnormal rhythms, either during induction or during surgery, ranging through nodal rhythm, premature ventricular contractions (some in the form of bigeminy), and some depression of sT segment in leads 2, 3, and avf. A normal ECG was obtained before the termination of operation. It was interesting that some of the obviously apprehensive patients did not exhibit any electrocardiographic changes either before or during anaesthesia, 
so that one might wonder if there could be some obscure underlying cardiac disease in those who did.

Gottlieb and Sweet ${ }^{3}$ maintain that rapid injection of atropine tends to produce tachycardia and ECG changes, but even though the atropine was administered intravenously in these cases, we did not notice any changes in the recording at that time, except in one case where a premature auricular contraction appeared. The solitary record of premature ventricular contractions occurring after succinylcholine does not, in our opinion, give the true picture. It is more likely that the irregular rhythm recorded over the period of oxygenation prior to intubation was due to the effect of the relaxant. Bradycardia was not seen after succinylcholine, but no doubt this was obscured by a previous administration of atropine. The effects of succinylcholine on the electrocardiogram have been described by Lupprian and Churchill-Davidson, ${ }^{4}$ and by Sagarminaga and Wynands. ${ }^{5}$ Katz ${ }^{6}$ suggests that the release of catecholamines by ganglionic stimulating action causes the arrhythmia.

As can be expected, endotracheal intubation caused the greatest incidence of cardiac arrhythmias. Many investigators have described this response. Reid and Bruce $^{7}$ say that it is due to stimulation of the respiratory mucosa. More recently, arrhythmias have been controlled by changing the anaesthetic being used, in order to block this reflex.8,9 Denson and Joseph ${ }^{10}$ have advocated adequate ventilation with oxygen prior to intubation to avoid the occurrence of cardiac irregularities, although we found that this did not prevent abnormal rhythm in some patients. Dripps and Vandam ${ }^{11}$ point out that minimal anaesthesia predisposes to a rise in arterial blood pressure and tachycardia, a dangerous occurrence in the presence of cardiac disease. Burstein et al. ${ }^{8}$ observed that arrythmias during intubation are more likely to occur during light anaesthesia. This observation is supported by Simpson. ${ }^{12}$

There is some significance in arrhythmias occurring in 12 patients immediately after intubation; the change is most likely associated with inflation of the cuff. Noble and Derrick ${ }^{13}$ recorded cardiac arrhythmia before, during, and after intubation, and found a higher incidence before the tube was inserted, but the greatest rate of tachycardia occurred about $1 \frac{1 / 2}{2}$ to 2 minutes after the cuff had been inflated. It is suggested that this manoeuvre produces even greater stimulation than intubation. Horton ${ }^{14}$ and Dance ${ }^{15}$ have found that tachycardia is a frequent sequel to intubation.

Given a cardiovascular system in the state of heightened sensitivity which often follows induction and intubation, the use of sympathomimetics can produce a dangerous situation. Even in the absence of cardiac arrhythmia, an elevated blood pressure could, according to Vick, ${ }^{16}$ increase the chance of the occurrence of abnormal heart action through stretching of the cardiac muscle, which increases the chance of automaticity. The important point in such a situation is that less epinephrine is required to initiate such an independent cardiac action, which would lead inevitably to a multifocal pacemaker. An attempt to correct the hypertension should therefore be made before the injection of local anaesthetic containing epinephrine. This we have done, and the surgeon was requested to wait until a satisfactory blood pressure level was reached. We 
found in some of the earlier cases that the injection of the local anaesthetic could produce or accentuate cardiac arrhythmias if it was done during a hypertensive state.

It has been established that the amount of local anaesthetic drug, the inclusion of epinephrine, the route and location, all carry important implications. The fact that lidocaine was used in this series may have had some effect in controlling the deleterious effects of the epinephrine. Harrison, Sprouse, and Morrow ${ }^{17}$ state that lidocaine has little effect on the systemic arterial pressure and little or no effect on the contractile force of the heart. Liberman et al., ${ }^{18}$ in more recent observations, suggest that lidocaine may decrease the rate of spontaneous depolarization of the automatic heart cells. The total permissible dose in an anaesthetized patient has not been established, according to Harrison, Sprouse, and Morrow, ${ }^{17}$ but an adult patient was given $500 \mathrm{mg}$ intravenously within the space of one hour for the control of arrhythmia without detectable signs of toxicity. We found it was unusual to get a marked rise in blood pressure and pulse rate following the subcutaneous injection of 2 per cent lidocaine and epinephrine 1:100,000, provided the systolic blood pressure was within the 90 to $120 \mathrm{~mm} \mathrm{Hg}$ range at the time of injection. The cardiovascular response to the topical application of cocaine epinephrine mixture was quite marked and in a few patients the blood pressure rose as high as 180 to $200 \mathrm{~mm}$ Hg. In observations on animals, Trendelenberg ${ }^{19}$ noted that cocaine increased both the plasma concentration of norepinephrine and the blood pressure response to it. He suggested that cocaine causes a super-sensitivity to norepinephrine by delaying its inactivation. Torda ${ }^{20}$ had found earlier that cocaine delayed the inactivation of epinephrine. Katz and Epstein ${ }^{6}$ also maintain that cocaine increases and prolongs the action of catecholamines, and they say this is due to the prevention of uptake of the latter.

In this clinical investigation, there has been an attempt to provide the necessary safeguards against the occurrence of cardiovascular changes which could manifest themselves in the presence of epinephrine. These safeguards are an adequate level of anaesthesia, prevention of hypoxia and hypercarbia by effective ventilation, and avoidance of hypertension by maintaining a systolic pressure between 85 and $95 \mathrm{~mm} \mathrm{Hg}$ wherever possible. It cannot be emphasised too strongly that constant vigilance is needed to ensure that only patients who are in a satisfactory physical condition are exposed to any operative procedure where the use of epinephrine is regarded as a necessary adjunct. The fact that the electrocardiographic abnormalities disappeared during or at the end of surgery should not be allowed to promote a climate of optimism concerning the cause of their occurrence. Finally, communication and understanding between surgeon and anaesthetist should be well established.

\section{SUMMARY}

A series of 167 cases is presented in which each patient underwent plastic surgery. The majority of the operations involved facial reconstruction. The aim of our investigation was to observe the effects on the cardiovascular system of 
epinephrine used during general anaesthesia. Electrocardiographic recordings were made during the course of the operations. The types of abnormal rhythm and the probable causes have been discussed. It is concluded that epinephrine may be used safely during general anaesthesia, provided certain important precautions are rigorously observed.

\section{RÉSUMÉ}

Le but de cette étude était d'observer les effets de l'épinéphrine sur le système cardiovasculaire durant l'anesthésie générale. Nous présentons une série de 167 malades opérés pour chirurgie plastique; la plupart de ces opérations étaient des réparations faciales. On enregistrait les tracés électrocardiographiques durant les opérations. On a étudié les types d'anomalies du rythme observées et leurs causes probable. On a conclu que l'épinéphrine peut être utilisée en toute sécurité durant l'anesthésie générale, à condition de maintenir un niveau suffisant d'anesthésie et de prévenir l'hypoxie et l'hypercardie par une ventilation efficace. On doit éviter l'hypertension et maintenir le systolique autant que possible entre 85 et $95 \mathrm{~mm} \mathrm{Hg}$. Il faut exercer une vigilance constante et s'assurer que seuls des malades en bonne condition physique soient soumis à un genre chirurgie où l'addition d'épinéphrine est considérée comme nécessaire. Bien que les anomalies de l'ECG disparaissent pendant ou après l'opération, ce n'est pas une raison pour créer un climat d'optimisme au sujet de la cause de ces anomalies.

\section{ACKNOWLEDGMENTS}

We are indebted to Dr. Harold Silver for his co-operation during the course of our investigations.

\section{REFERENCES}

1. Katz, Ronald L. Epinephrine and plv-2: Cardiac Rhythm and Local Vasoconstrictor Effects. Anesthesiology. 5: 619 (1965).

2. Goldman, Mervin J. Principles of Clinical Electrocardiography. 6th ed. (California: Lange Medical Publications, 1967).

3. Gotrlieb, J. D. \& Sweet, R. B. The Antagonism of Curare: The Cardiac Effects of Atropine and Neostigmine. Canad. Anaesth. Soc. J. 10: 114 (1963).

4. Lupprian, K. G. \& Churchill-Davidson, H. C. Effect of Suxamethonium on Cardiac Rhythm. Brit. Med. J. ii: 1774 (1960).

5. Sagarminaca, J. \& Wynands, J. E. Atropine and the Electrical Activity of the Heart during Induction of Anaesthesia in Children. Canad. Anaesth. Soc. J. 10: 328 (1963).

6. Katz, Ronald L. \& Epstein, Ralph A. The Interaction of Anesthetic Agents and Adrenergic Drugs to Produce Cardiac Arrhythmias. Anesthesiology. 29: 763 (1968).

7. ReID, L. C. \& BrucE, D. E. Irritation of the Respiratory Tract and Its Reflex Effect upon the Heart. Surg. Gynec. \& Obst. 70: 157 (1940).

8. Burstein, Chafles L.; Lo Pinto, F. J.; \& Newman, W. Electrocardiographic Studies during Endotracheal Intubation: Effects during Routine Technics. Anesthesiology 11: 224 (1950).

9. Arcuni, R. A.; Newman, W.; \& Burstein, C. L. Electrocardiographic Studies during Endotracheal Intubation: Effects during General Anesthesia and Hexylcaine Hydroxide Topical Spray. Anesthesiology. 14: 46 (1953).

10. Denson, J. S. \& Joseph, S. I. Cardiac Rhythm and Endotracheal Intubation. Anesthesiology. 15: 650 (1954).

11. Dripps, R. D. \& Vandam, L. D. Anesthetic Management of Patients with Heart Disease. Circulation. 5: 927 (1952). 
ROBERTS \& BOYAGIAN: ELECTROCARDIOGRAPHIC CHANGES WITH EPINEPHRINE 601

12. Simpson, K. Deaths from Vagal Inhibition. Lancet. 1: 558 (1949).

13. Noble, Marvin J. \& Dernick, William S. Changes in the Electrocardiogram during Induction of Anaesthesia and Endotracheal Intubation. Canad. Anaesth. Soc. J. 6: 267 (1959).

14. Horton, J. A. G. Electrocardiagraphic Findings during Laryngoscopy and Endotracheal Intubation. Brit. J. Anaesth. 27: 326 (1955).

15. Dance, C. L., Jr. Electrocardiographic Studies during Endotracheal Intubation: Evipal Sodium Induction. Anesthesiology. 17: 730 (1956).

16. VICK, R. L. Effects of Increased Transmural Pressure upon Atrial and Ventricular Rhythm in the Dog Heart-Lung Preparation. Circulation. 13: 39 (1963).

17. Harrison, D. C.; Sprouse, J. H.; \& Morrow, A. G. The Anti-Arrhythmic Properties of Lidocaine and Procaine Amide: Clinical and Physiological Studies of Their Cardiovascular Effects in Man. Circulation. 28: 486 (1963).

18. Liberman, N. A.; Hahris, R. S.; Katz, R. L.; et al. Effects of Lidocaine on the Electrical and Mechanical Activity of the Heart. Am. J. Cardiol. 22: 375 (1968).

19. Trennelenberg, U. The Supersensitivity Caused by Cocaine. J. Pharmacol. \& Therap. 125: 55 (1959).

20. Torda, C. Effects of Cocaine on the Inactivation of Epinephrin and Sympathin. J. Pharmacol. \& Therap. 78: 331 (1943). 